\section{Chinese nature reserve continues experimental use of fire to benefit the threatened Cycas panzhihuaensis}

On 30-31 January 2016 China's Panzhihua Cycad National Nature Preserve successfully carried out its 4 th round of prescribed fire to improve the habitat of the threatened Panzhihua cycad Cycas panzhihuaensis. This cycad is categorized as Vulnerable on the IUCN Red List and as a Class I National Protected Plant of China. The number of populations has shrunk from 16 to one and the size of the one remaining population has shrunk by more than $80 \%$ over 3 generations as a result of poaching during the 1980s and habitat destruction by mining activities.

The Panzhihua cycad is restricted to the hot, dry savannah along the valleys of the Jinsha River and its tributaries in and around Panzhihua City. This habitat has been subjected historically to frequent wildfires. However, since the establishment of the area as a municipal preserve in 1983 (upgraded to a National Nature Preserve in 1996), fire has been excluded in accordance with national policy to prevent fires in all protected areas. After more than 2 decades without fire the Panzhihua cycad population within the preserve started to show signs of decline as a result of competition with trees. Permission was therefore obtained from the State Forestry Administration to carry out prescribed burning of 3.5 ha in 2010, 10 ha in 2011, and 5.1 ha in 2012, in north, south and south-east-facing areas, respectively. However, non-burn controls were not studied and therefore the effects of the fires remained unclear.

The 4 th prescribed fire, however, was carried out in areas with known time-to-last-fire and included non-burn control plots. In addition, $1 \mathrm{~cm}$ thick steel plates painted with 19 temperature sensitive paints $\left(107-538^{\circ} \mathrm{C}\right)$ were placed at ground level throughout the 24 burn areas to measure fire intensity. A replicated seed experiment was set up to examine the effect of fire on seed germination rates. The nature preserve harbours a total of 521 plant species from 111 families and 361 genera, including 25 other threatened plants, and the research will also provide information on the response of these plants to fire.

Knowledge of the effect of fire on the Panzhihua cycad will be used to design a management plan for the species and will also provide scientific data for a reconsideration of the policy on prescribed fire in nature reserves, as certain habitat types and species are dependent upon periodic burning for their continued existence. A programme to introduce fire periodically, under controlled conditions, will help to conserve C. panzhihuaensis and its remaining habitat as well as other species and habitats that evolved with and depend upon fire.
H. Liu acknowledges support from the Guangxi Science and Technology Bureau (grant no 12217-04).

HoNG LIU International Center for Tropical Botany and the Department of Earth and Environment, Florida International University, Miami, Florida, USA, Fairchild Tropical Botanic Garden, Coral Gables, Florida, USA, and College of Forestry, Guangxi University, China E-mail hliu@fiu.edu

WUying LiN and XiaOYa Li Fauna \& Flora International, China Programme

\section{New tree species described from the Western Ghats, India}

The wet evergreen rainforests of the Western Ghats of India have undergone serious fragmentation. While the loss of primary forest continues, scientists are beginning to realize they have underestimated the species diversity and evolutionary uniqueness of this ecosystem. Biologists have, for example, recently discovered several new species of amphibians and reptiles, some with unique evolutionary histories and novel breeding behaviours.

A new species in the genus Miliusa, an understorey tree of the Annonaceae (custard apple) family, was recently discovered during an expedition to Kudremukh peak in 2013, and subsequent expeditions in 2014. This new species has been named Miliusa malnadensis (Page \& Nerlekar, 2016, Phytotaxa, 245, 79-83). It is restricted to montane evergreen forests at a narrow elevational zone of 1,200-1,500 m.

This tree species may have previously gone unnoticed because of its restricted distribution and sparse and sporadic flowering. It may also have been mistaken for its morphologically similar congener, Miliusa wightiana. The new discovery makes southern India the centre of diversity of this genus. There are also likely to be other tree species yet to be discovered and, like M. malnadensis, it will be difficult to assign an IUCN Red List status to such species without information on range or population size.

The publication of the discovery of this new species was made possible through the support of the Conservation Leadership Programme (www.conservationleadershippro gramme.org), which is currently supporting a project to carry out distribution and population status assessments of selected endemic trees of the Western Ghats. We hope that the discovery of M. malnadensis and other new species will help in some way to save this unique and diverse ecosystem.

NAVENDU PAGE Center for Ecological Sciences, Indian Institute of Science, Bangalore, Karnataka, India E-mail navendu.page@gmail.com 